\title{
Measurement of Retinal Blood Flow Using Fluorescently Labeled Red Blood Cells $s^{1,2,3}$
}

\author{
(D)Tess E. Kornfield and ${ }^{(D E}$ Eric A. Newman
}

DOI:http://dx.doi.org/10.1523/ENEURO.0005-15.2015

Department of Neuroscience, University of Minnesota, Minneapolis, Minnesota 55455

\begin{abstract}
Blood flow is a useful indicator of the metabolic state of the retina. However, accurate measurement of retinal blood flow is difficult to achieve in practice. Most existing optical techniques used for measuring blood flow require complex assumptions and calculations. We describe here a simple and direct method for calculating absolute blood flow in vessels of all sizes in the rat retina. The method relies on ultrafast confocal line scans to track the passage of fluorescently labeled red blood cells (fRBCs). The accuracy of the blood flow measurements was verified by (1) comparing blood flow calculated independently using either flux or velocity combined with diameter measurements, (2) measuring total retinal blood flow in arterioles and venules, (3) measuring blood flow at vessel branch points, and (4) measuring changes in blood flow in response to hyperoxic and hypercapnic challenge. Confocal line scans oriented parallel and diagonal to vessels were used to compute fRBC velocity and to examine velocity profiles across the width of vessels. We demonstrate that these methods provide accurate measures of absolute blood flow and velocity in retinal vessels of all sizes.
\end{abstract}

Key words: blood flow; methods; rat; red blood cell velocity; retina

\section{Significance Statement}

Accurately measuring blood flow in the retina is an important challenge, as blood flow reflects the health of retinal tissue and is disrupted in many diseases. Existing techniques for measuring blood flow are limited due to the complex assumptions and calculations required. The techniques described here use fluorescently labeled blood cells combined with ultrafast microscopy measurements to overcome these limitations. The measurement techniques were validated by several methods. Blood flow and blood velocity were assessed in blood vessels of all sizes in the rat. Accurate measurement of retinal blood flow can be used to track disease progression and inform treatment.

\section{Introduction}

Blood flow is closely tied to the metabolic state of cells in the CNS (Attwell et al., 2010) and is disrupted in many

Received January 16, 2015; accepted April 21, 2015; First published April 29, 2015.

${ }^{1}$ The authors declare no competing financial interests.

${ }^{2}$ Author Contributions: T.E.K. and E.A.N. designed the research; T.E.K. performed research; T.E.K. analyzed data; T.E.K. and E.A.N. wrote the paper.

${ }^{3}$ This work was supported by National Institutes of Health Grant EY-004077 and Fondation Leducq.

Acknowledgements: The authors thank Michael Burian for his invaluable technical assistance; and Kyle Biesecker, Michael Burian, Joanna Kur, and Anja Srienc for their helpful discussions and for reviewing the manuscript.
CNS disorders including stroke and Alzheimer's disease (Girouard and ladecola, 2006). In the retina, blood flow is compromised in diabetic retinopathy (Garhofer et al., 2004a), glaucoma (Garhöfer et al., 2004b), and retinal vessel occlusion (Osborne et al., 2004), among others,

Correspondence should be addressed to: Eric A. Newman, Department of Neuroscience, University of Minnesota, Minneapolis, MN 55455. E-mail: ean@umn.edu.

DOI:http://dx.doi.org/10.1523/ENEURO.0005-15.2015

Copyright (C) 2015 Kornfield and Newman

This is an open-access article distributed under the terms of the Creative Commons Attribution 4.0 International, which permits unrestricted use, distribution and reproduction in any medium provided that the original work is properly attributed. 
and can lead to severe vision loss. Reductions in blood flow and blood vessel responsiveness can occur in the early stages of disease, and accurate measurement of retinal blood flow in humans and animal models can be used to track disease onset and progression and to inform treatment.

Many methods have been developed for measuring blood flow in the retina (Pournaras and Riva, 2013). Estimates of blood flow can be made by observing the deposition of large $(\sim 15 \mu \mathrm{m})$ microspheres (Ahmed et al., 2001), by measuring transit time of labeled plasma, and by measuring oxygenation with functional magnetic resonance imaging (Cheng et al., 2006; De la Garza et al., 2011) or phosphorescence lifetime imaging (Shahidi et al., 2006, 2009; Wanek et al., 2011). More commonly, blood flow is computed as the product of blood velocity and vessel cross-sectional area, each measured independently. Vessel diameter can be measured from fundus images by using the retinal vessel analyzer or the scanning laser ophthalmoscope, or by using confocal line scans. Velocity can be measured with bidirectional laser Doppler velocimetry, frequency domain optical coherence tomography (FD-OCT), video analysis of fluorescently labeled red blood cells (fRBCs) or small microspheres (Rovainen et al., 1993; Lorentz et al., 2008), or line scan analysis of RBC streaks (Kleinfeld et al., 1998; Hutchinson et al., 2006; Schaffer et al., 2006; Autio et al., 2011; Kim and Filosa, 2012; Santisakultarm et al., 2012).

Noninvasive optical techniques for measuring retinal blood flow have gained favor due to their applicability to human subjects. Recent technological advances include the Canon laser Doppler blood flowmeter, a commercially available instrument that uses Doppler velocimetry and diameter measurements to calculate blood flow (Garcia et al., 2002; Guan et al., 2003; Gilmore et al., 2005; Sehi et al., 2012). FD-OCT, which computes blood flow by integrating velocity across the vessel width (Wang et al., 2007, 2009; Doblhoff-Dier et al., 2014; Leitgeb et al., 2014; Shahidi et al., 2014) is also used. However, a major drawback of most optical methods is that blood flow measurements are limited to vessels greater than $\sim 30 \mu \mathrm{m}$ in diameter; smaller vessels require higher-resolution techniques.

To this end, we have developed techniques for measuring blood flow in the retinal vessels of the rat, which range from $\sim 4$ to $\sim 70 \mu \mathrm{m}$ in diameter. We measure blood flow by visualizing the passage of fRBCs. This technique is relatively noninvasive, requiring only withdrawal and reinjection of blood. Our measurements are direct; minimal computation and few assumptions are needed to calculate absolute flow. Imaging of fRBCs has been used previously to measure blood flow in small vessels where blood velocity is low and the passage of individual cells is easily imaged. Here, ultrafast confocal line scans capture the passage of high-velocity fRBCs in large retinal blood vessels. We use this technique to measure total blood flow in the retina, blood flow changes in response to functional challenge, and blood velocity profiles across the width of vessels. Absolute blood flow can be calculated easily and accurately with this technique.

\section{Materials and Methods}

\section{In vivo preparation}

Blood flow was measured in rats using an in vivo retinal preparation that has been described previously (Srienc et al., 2012; Kornfield and Newman, 2014). All animal procedures were performed in accordance with the regulations of the University of Minnesota Animal Care Committee. Briefly, 2- to 3-month-old, male, Long-Evans rats were anesthetized with $2 \%$ volatile isoflurane in $30 \%$ oxygen and $70 \%$ nitrogen, and tracheotomized for artificial ventilation. The femoral vein and artery were cannulated for drug injection and the measurement of blood pressure, respectively. Following surgery, isoflurane was incrementally discontinued, and anesthesia was maintained using $\alpha$-chloralose $(800 \mathrm{mg} / \mathrm{kg}$ bolus, $550 \mathrm{mg} / \mathrm{kg} / \mathrm{h}$ maintenance; $\alpha$-chloralose-HBC complex; catalog \# C8849, Sigma-Aldrich; the molecular weight of uncomplexed $\alpha$-chloralose is $10 \%$ that of $\alpha$-chloralose-HBC Complex). Pupils were dilated with atropine (atropine sulfate ophthalmic solution 1\%, National Drug Code 61314303-02, Falcon Pharmaceuticals), and a contact lens was placed over the eye. Animals were secured to the stage of an upright confocal microscope (FV1000, Olympus) using a custom holder. The paralytic agent gallamine triethiodide was given $(20 \mathrm{mg} / \mathrm{kg}$ bolus, $20 \mathrm{mg} / \mathrm{kg} / \mathrm{h}$ maintenance; catalog \#G8134, Sigma-Aldrich) to reduce eye movement. During experimentation, animals were ventilated at 55 breaths $/$ min with a tidal volume of $\sim 3.4 \mathrm{ml}$ and $2 \mathrm{mmHg}$ end-expiratory pressure. A deep breath of 30 $\mathrm{cmHg}$ was given every $\sim 5$ min to maintain full lung capacity. Body temperature was maintained at $37^{\circ} \mathrm{C}$. Arterial blood pressure (Pressure Monitor BP-1, World Precision Instruments), oxygen saturation (MouseOx, Starr Life Sciences), and end-tidal $\mathrm{CO}_{2}$ (MicroCapStar, CWE) were monitored continuously, and data were collected only when physiological parameters were within normal range (blood pressure, $95-130 \mathrm{mmHg}$; oxygen saturation, $>92 \%$, end-tidal $\mathrm{CO}_{2}, 35-45 \mathrm{mmHg}$ ) and stable. Following experimentation, $\sim 1 \mathrm{ml}$ of blood was withdrawn from the arterial line for in vitro assessment of RBCs per blood volume and the fRBC/RBC ratio. The animal was killed by injection of potassium chloride (2 $\mathrm{mEq} / \mathrm{kg}$ ).

\section{Fluorescent labeling of red blood cells}

The RBC labeling procedure has been described previously (Kornfield and Newman, 2014). Briefly, blood was withdrawn from each animal at the beginning of the experiment, and RBCs were isolated and resuspended in blood plasma buffer (BPB; in mM: $128 \mathrm{NaCl}, 15$ glucose, $10 \mathrm{HEPES}, 4.2 \mathrm{NaHCO} 3,3 \mathrm{KCl}, 2 \mathrm{MgCl}$, and $1 \mathrm{KH} 2 \mathrm{PO} 4$, pH 7.4; Khoobehi et al., 2003). Cells were incubated for 5 min with the lipophilic dye carbocyanide 1,1'-dioctadecyl3,3,3',3'-tetramethylindodicarbocyanine, 4-chlorobenzenesulfonate salt solid (DiD; catalog \#D-7757, Invitrogen). Cells were washed three times to removed unbound dye. Labeled cells were then reinjected into the animal at volumes appropriate for the experiment. fRBC/RBC ratios ranged from $0.1 \%$ to $1.8 \%$. Higher ratios were used to 

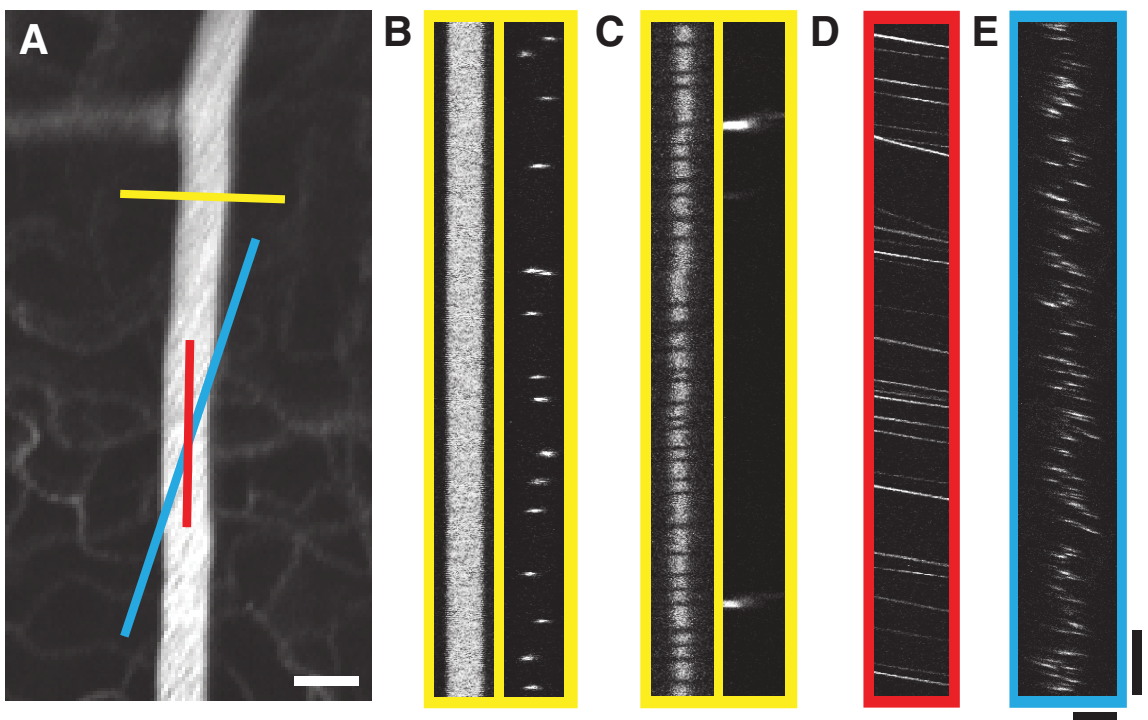

Figure 1 Measurement of RBC flux and velocity using confocal line scans. $\boldsymbol{A}, \mathrm{A}$ confocal reference image showing the three line scan configurations used for measuring flux and diameter (yellow line), and velocity (red and blue lines). Scale bar, $50 \mu \mathrm{m}$. $\boldsymbol{B}, \mathbf{A}$ line scan image of a large vessel acquired with a perpendicular line scan (yellow line in $\boldsymbol{A}$ ). The $y$-axis represents time, and the $x$-axis represents distance. Vessel diameter is measured by imaging FITC-labeled plasma (left), and fRBC flux is measured by imaging fRBCs (right). $\boldsymbol{C}$, A line scan image of a capillary acquired with a perpendicular line scan (yellow line in $\boldsymbol{A}$ ). Vessel diameter and total RBC flux is measured by imaging FITC-labeled plasma (left), and fRBC flux is measured by imaging labeled RBCs (right). $\boldsymbol{D}$, A line scan image of a large vessel acquired with a line scan parallel to the vessel (red line in $A$ ). fRBC velocity is measured from the slope of fRBC streaks, where velocity is inversely proportional to the streak angle. $\boldsymbol{E}$, A line scan image of a large vessel acquired with a line scan oriented diagonal to the vessel (blue line in $\boldsymbol{A}$ ). $\mathrm{fRBC}$ velocity across the width of the vessel is measured from the slope of the fRBC streaks along the $x$-axis of the image. Scale bars in $\boldsymbol{E}$ refer to $\boldsymbol{B}-\boldsymbol{E}$. Vertical calibration: $\boldsymbol{B}, 15.5 \mathrm{~ms} ; \boldsymbol{C}, 77.5 \mathrm{~ms} ; \boldsymbol{D}, 18 \mathrm{~ms} ; \boldsymbol{E}, 30.5 \mathrm{~ms}$. Horizontal scale bars: $\boldsymbol{B}, 60.5 \mu \mathrm{m} ; \boldsymbol{C}, 10.5 \mu \mathrm{m} ; \boldsymbol{D}, 38 \mu \mathrm{m} ; \boldsymbol{E}, 121.5 \mu \mathrm{m}$.

measure velocity and flux in small vessels, and lower ratios were used to measure flux in large vessels.

\section{RBC flux and diameter measurements}

RBC flux and blood vessel diameter were measured and analyzed as described previously (Kornfield and Newman, 2014). Briefly, fluorescein isothiocyanate (FITC) dextran $(2000 \mathrm{kDa} ; 1 \mathrm{ml}$ of $3 \%$ solution; catalog \#FD200S, Sigma-Aldrich) was injected intravenously for visualization of intraluminar diameter. Line scans were oriented perpendicular to the axis of the blood vessel (Fig. 1A, yellow line). Vessel diameter and fRBC flux were imaged simultaneously with 488 and $635 \mathrm{~nm}$ excitation light, respectively. Line scans in vessels $<10 \mu \mathrm{m}$ in diameter were acquired at $\sim 650 \mathrm{~Hz}$ for at least $45 \mathrm{~s}$. Line scans in vessels $>10 \mu \mathrm{m}$ in diameter were acquired at $4200 \mathrm{~Hz}$ for $8 \mathrm{~s}$ (scan time was limited by the confocal microscope software). The ultrafast acquisition rate in large vessels was necessary to capture the passage of high-velocity RBCs. Diameter was extracted from FITC line scans (Fig. $1 B, C)$ using custom MATLAB software that automatically measured the distance between vessel borders. fRBC flux was computed as cells per second by identifying and counting bright spots in the line scan images (Fig. 1C).

\section{Velocity measurements}

Blood velocity was measured with line scans oriented either parallel (Fig. $1 A$, red line) or diagonal (Fig. 1A, blue line) to the blood vessel. In velocity line scan images (Fig.
$1 D, E)$, fRBCs appear as diagonal streaks where the angle of the streak is inversely proportional to velocity (Dirnagl et al., 1992). Measurement of streak angle was performed using the Radon function, and the open source code for velocity calculation (Chhatbar and Kara, 2013) was modified to fit the current dataset. For diagonal line scan data, velocity was calculated at 10 locations along the length of the line. Vessel diameter was calculated from reference images of the FITC-filled vessel lumen. Due to chromatic aberration of the rat lens, the 488 and 635 images did not align perfectly. For this reason, all data are aligned to the furthest edges of the vessel that yielded usable velocity data.

\section{Functional challenge}

Hyperoxia was generated by increasing the oxygen content of the ventilation gas from $30 \%$ to $60 \%$ and reducing nitrogen accordingly. Hypercapnia was generated by replacing $5 \%$ of the nitrogen with $\mathrm{CO}_{2}$. End-tidal $\mathrm{CO}_{2}$ reached $\sim 60 \mathrm{mmHg}$ during hypercapnia. Blood pressure remained within the normal range during both interventions. Both blood flow and blood vessel diameter were measured in primary arterioles approximately every $30 \mathrm{~s}$ during the challenge sessions, which typically lasted 13 $\mathrm{min}$. Baseline diameter and flow values were collected for at least 2 min prior to challenge onset. Hyperoxia and hypercapnia were maintained for at least $3 \mathrm{~min}$, after which inhalation gas mixtures were returned to normal, and flow and diameter recovery were tracked. 


\section{Calculation of $\mathrm{fRBC} / \mathrm{RBC}$ ratio and measurement of RBCs per blood volume}

The $\mathrm{fRBC} / \mathrm{RBC}$ ratio was calculated using both in vivo flow cytometry and a slide-based cell-counting method. To calculate the $\mathrm{fRBC} / \mathrm{RBC}$ ratio using in vivo flow cytometry, total RBC flux and fRBC flux were acquired simultaneously with perpendicular line scans across capillaries, where blood cells move single file (Fig.1C). Labeled and total cells per second were counted, and their ratio was calculated.

The $\mathrm{RBBC} / \mathrm{RBC}$ ratio and the number of cells per blood volume were also calculated using a hemocytometer (catalog \#3102, Hausser Scientific). Blood withdrawn from the rat at the end of each experiment was diluted 1:300 with BPB and loaded onto an unlined two-chamber hemocytometer. An upright fluorescence microscope with a $20 \times$ water-immersion objective was used to visualize labeled and unlabeled cells. Ten to 20 fields were imaged in each of the two chambers of the hemocytometer. Filter cubes of 488 and $635 \mathrm{~nm}$ were used to visualize RBCs and fRBCs, respectively. Using a custom MATLAB algorithm, these images were intensity rescaled, median filtered, and background subtracted. The circular RBCs in each channel were identified and counted. Each imaged field of the hemocytometer represents a defined volume, so these cell counts were used to calculate the number of cells per volume as well as the fRBC/RBC ratio. Values from the two chambers did not differ, and the data were pooled.

\section{Statistics}

Data are expressed as the mean \pm SD. Significance was defined as $p<0.05$. Two-tailed $t$ tests were used to compare the $\mathrm{fRBC} / \mathrm{RBC}$ ratios calculated from in vivo flow cytometry and in vitro cell counting. Pearson linear correlations were used to quantify the relationship between blood flow measurements calculated two ways, and to compare flow rates in parent and daughter vessels at bifurcations. Repeated-measures ANOVAs were used to assess changes in diameter and flow in response to hyperoxic and hypercapnic challenge. Statistical analysis was performed using GraphPad Prism (version 5) and MATLAB.

\section{Results}

We have measured blood flow in rat retinal blood vessels by introducing fluorescently labeled red blood cells into the vasculature (Fig. 1). fRBC flux was measured with perpendicularly oriented confocal line scans in vessels ranging from primary arterioles and venules to capillaries by counting individual fRBCs as they passed through a vessel (Fig. $1 A$, yellow line, $B, C$ ). In small vessels where RBCs move single file, fRBC flux and total RBC flux can be captured simultaneously (Fig. 1C). RBC velocity was measured within vessels with confocal line scan lines oriented parallel to the vessel lumen (Fig. $1 A$, red line, D). Velocity was also measured across the full width of blood vessels with diagonally oriented line scan lines (Fig. 1A, blue line, E).

\section{fRBC/RBC ratio and $\mathrm{RBC}$ ser blood volume measured in vivo and in vitro}

The methodology described here allows for the measurement of absolute blood flow, expressed in microliters per minute. Blood flow measurements obtained by counting fRBCs require knowledge of the $\mathrm{fRBC}$ flux, the fRBC/RBC ratio, and the number of RBCs per volume of blood. The $\mathrm{fRBC} / \mathrm{RBC}$ ratio was calculated using in vivo flow cytometry by simultaneously counting fRBCs and unlabeled RBCs passing single file through a capillary (Fig. 1C) for at least $2 \mathrm{~min}$. The fRBC/RBC ratio was also calculated from ex vivo counts made with a hemocytometer. The fRBC/ $\mathrm{RBC}$ ratio measured in vivo equaled the ratio measured $e x$ vivo in three of four experiments [in vivo vs in vitro: $1.64 \pm$ $0.35 \%(n=8)$ vs $1.52 \pm 0.35 \%(n=9) ; 1.50 \pm 0.42 \%$ $(n=9)$ vs $1.52 \pm 0.60 \%(n=16) ; 0.69 \pm 0.24 \%(n=9)$ vs $0.71 \pm 0.35 \%(n=32) ; p=$ n.s.]. The experiment where in vivo and in vitro values were not statistically equal was one with a very low $\mathrm{FRBC} / \mathrm{RBC}$ ratio [0.53 \pm $0.36 \%(n=8)$ vs $0.22 \pm 0.22 \%(n=36) ; p<0.01$, two-tailed $t$ tests]. fRBC/RBC ratios ranged from $0.1 \%$ to $1.8 \%$.

The number of RBCs per microliter of blood was calculated for each experiment from the total number of RBCs in the hemocytometer, which has a known volume. In our experiments, the mean number of RBCs per microliter was $9.6 \pm 1.1$ million $(n=15)$, fitting within the accepted range of 7-10 million RBCs/ $\mu$ l.

\section{Blood flow calculated from RBC flux and velocity}

Blood flow $(Q)$ was calculated by two independent methods that were then compared, allowing us to validate the measurements of diameter, flux, and velocity. In the first method, fRBC flux was used to compute blood flow with the following equation:

$$
Q=(f R B C s / s) *(R B C s / f R B C s) /(R B C s / v o l),
$$

where the number of fRBCs per second was determined from line scans perpendicular to blood vessels, and RBC/ fRBC and RBC/volume ratios were both determined from hemocytometer measurements. In the second method, RBC velocity and vessel diameter were measured using confocal line scans parallel and perpendicular to blood vessels, respectively. Blood flow was calculated from the following equation:

$$
Q=V * A
$$

where $V$ is velocity, and $A$ is the luminal cross-sectional area. $V$ was measured from luminal line scans in the center of blood vessels, where the slope of fRBC streaks is inversely proportional to velocity. As discussed below, this yielded velocities that approximated the average RBC velocity within the vessel.

Blood flow was calculated by these two methods in vessels with a range of diameters and flow rates. The two methods yielded blood flow values that were highly correlated (Fig. 2; $R^{2}=0.982 ; p<0.001 ; n=15$; Pearson linear correlation) with a slope deviating from unity by only 0.13 . Because fRBC flux, blood velocity, blood vessel diameter, and blood cell counts are all measured inde- 


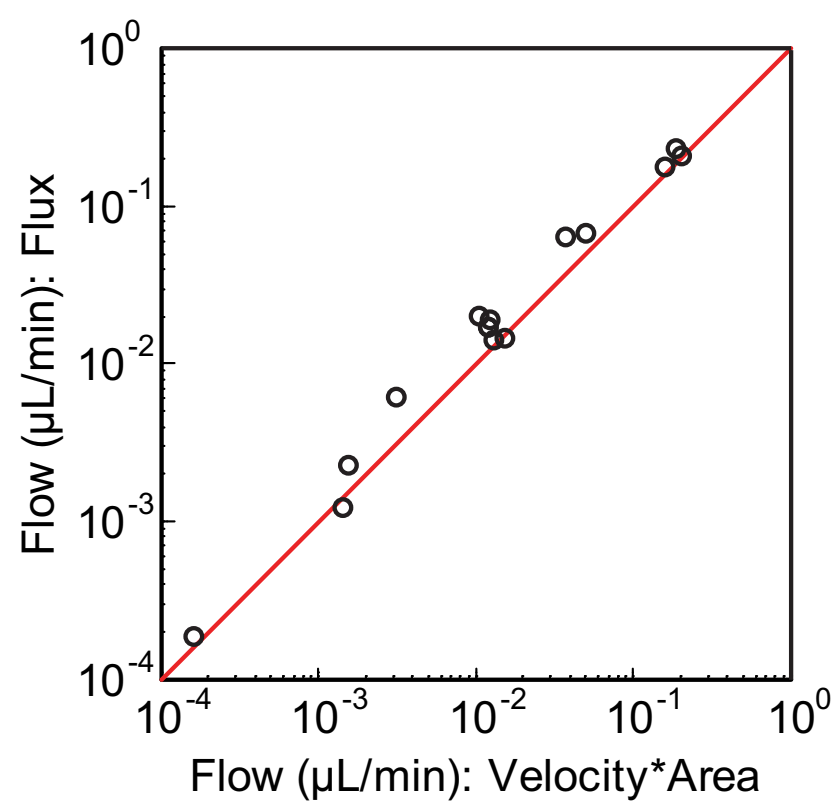

Figure 2 Blood flow calculated using two independent methods. Flow is calculated from fRBC flux ( $y$-axis), and velocity and vessel cross-sectional area ( $x$-axis). Each data point represents a single vessel. The red line represents unity.

pendently, the highly correlative relationship between the flow values confirms the validity of our methods.

\section{Blood flow at bifurcations}

We measured fRBC flux in parent and daughter vessels at bifurcations (Fig. $3 A$ ) to further validate the blood flow measurement technique. The sum of the RBC flux in the two daughter vessels should equal the flux in the parent vessel. This technique has been used previously to validate blood flux measurements (Parthasarathi et al., 1999). For all bifurcations studied, the sum of the fluxes in the daughter vessels was nearly identical to that of the parent vessel (Fig. 3B). This was true for vessels with a range of fluxes. The parent and daughter fluxes were highly corre- lated (Fig. 3B; $R^{2}=0.995, p<0.001 ; n=6$; Pearson linear correlation) with a slope deviating from unity by only 0.12 . The ratio of the flux in the parent vessel to the sum of the fluxes in the two daughter branches was 0.89 (Fig. $3 C$ ). Parent vessels averaged $9.3 \pm 3.5 \mu \mathrm{m}$, and daughter vessels averaged $8.4 \pm 2.9 \mu \mathrm{m}$ in diameter. The ratio of the diameter of the parent vessel to the sum of the diameters of the daughter vessels was 0.54 (Fig. $3 C$ ).

\section{Total retinal blood flow}

Total retinal blood flow was measured by summing the flow in all primary arterioles or venules emerging from the optic disk. Flow in these primary vessels was predictably dependent upon their diameter and type (Fig. 4A). The flow in individual primary retinal arterioles and venules averaged $0.42 \pm 0.25$ and $0.40 \pm 0.25 \mu \mathrm{l} / \mathrm{min}$, respectively. The diameter of the arterioles and venules averaged $30.0 \pm 6.7$ and $46.5 \pm 16.5 \mu \mathrm{m}(n=4$ retinas, 32 arterioles and 29 venules). The ratio of the number of arterioles to venules in this sample was 1.10. The relationship between flow and diameter can be described roughly by power functions with exponents of $2.30\left(R^{2}=0.65\right)$ and $2.23\left(R^{2}=0.79\right)$, respectively, for arterioles and venules. These values are similar to the exponents of 2.76 and 2.84 , respectively, reported previously for the human retina (Riva et al., 1985).

Because all blood that enters the retina through arterioles must leave it through venules, we expected that total blood flow in arterioles would equal the total blood flow in venules. To calculate the total blood flow in these vessels, we summed the individual flows of all arterioles and venules in the retina. Arteriole flow averaged $3.34 \mu \mathrm{l} / \mathrm{min}$, while venule flow averaged $2.93 \mu \mathrm{l} / \mathrm{min}$. The ratio of arteriole/venule blood flow was 1.13 for the three retinas examined (Fig. 4B).

Total retinal blood flow, calculated as the average of arteriole and venule flows, was $1.34,4.22$, and $3.85 \mu \mathrm{l} / \mathrm{min}$ for the three retinas examined, with a mean of $3.14 \mu \mathrm{l} / \mathrm{min}$. A large variation in total blood flow between individuals has also been observed in human retinas (Garhofer et al., 2012; Tayyari et al., 2014).
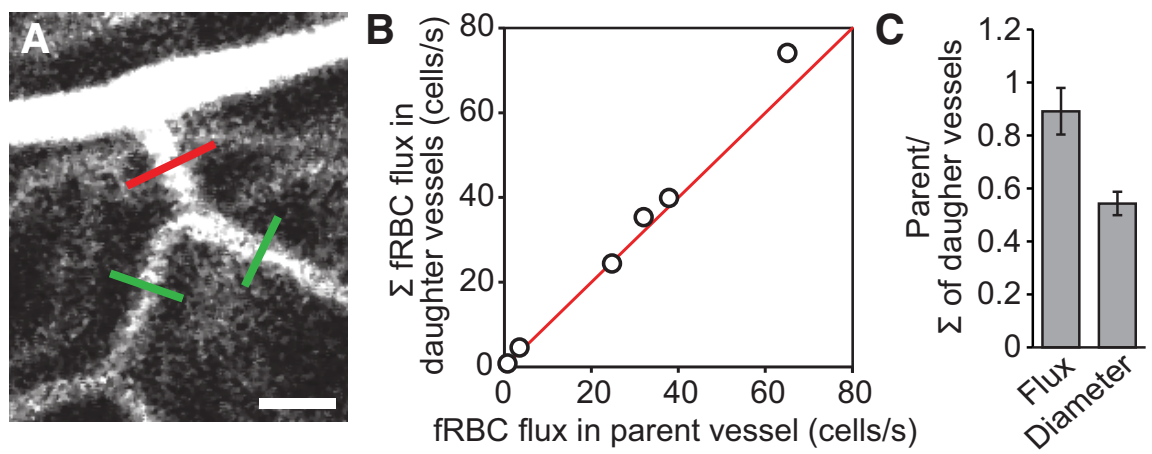

Figure $3 \mathrm{RBC}$ flux and diameter at vessel bifurcations. $\boldsymbol{A}$, Confocal reference image showing a typical bifurcation. The red line represents the confocal line scan across the parent vessel, and the green lines represent the line scans across the two daughter vessels. Scale bar, $40 \mu \mathrm{m}$. $\boldsymbol{B}$, The mean RBC flux for the parent vessel is plotted against the sum of RBC fluxes in the daughter vessels for six bifurcating vessels. The red line represents unity. $\boldsymbol{C}$, The ratio of the parent to the sum of daughter vessels for RBC flux and vessel diameter. 

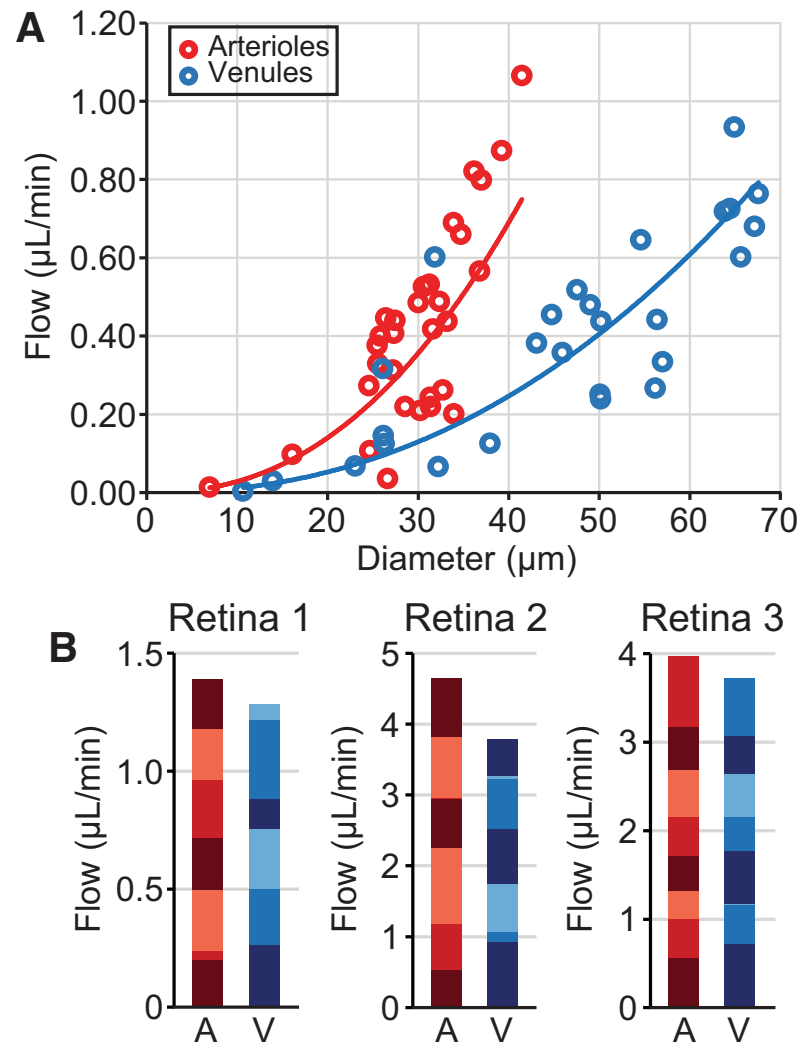

Figure 4 Total retinal blood flow. $\boldsymbol{A}$, Blood flow in individual primary arterioles (red) and venules (blue) emerging from the optic disk, plotted against vessel diameter and fit with power functions (see text for details). $\boldsymbol{B}$, Total blood flow in three retinas. Left columns represent arterioles $(A)$, and right columns represent venules (V). Each color block indicates the flow in an individual vessel. The full bar height is the sum of all individual flows, corresponding to the total blood flow in arterioles or venules in a retina.

\section{Functional challenge}

We challenged animals with hyperoxia and hypercapnia, two stimuli known to affect retinal blood flow, to confirm that our measurements are sensitive to changes in blood flow. Diameter and blood flow were measured in primary arterioles before, during, and after functional challenge.

Hyperoxia, generated by raising inhaled $\mathrm{O}_{2}$ from $30 \%$ to $60 \%$, constricted vessels and decreased blood flow (Fig. $5 A)$. Arteriole constrictions averaged $6.4 \pm 2.3 \%$, a significant reduction from baseline diameters $(p<0.01$, repeated-measures ANOVA; $n=4$ ), and blood flow decreased by an average of $15 \pm 3.8 \%$ from baseline (Fig. $5 B ; p<0.05$ ). The changes in diameter and blood flow had a slow onset, taking $\sim 170 \mathrm{~s}$ to reach steady-state values. Following the return to normoxia, diameter and flux moved toward baseline, although only diameter fully returned to baseline within the 5 min recovery period.

Hypercapnia, generated by breathing $5 \% \mathrm{CO}_{2}$, triggered a dilation of $59.7 \pm 12.1 \%$ and a blood flow increase of $115.2 \pm 17.0 \%$ (Fig. $5 C, D$ ), values that were greater than baseline levels $(p<0.001$ and $p<0.01$, respectively; $n=3$ ). The blood flow changes were faster than for hyperoxia, taking $\sim 45$ seconds to peak. Diameter and flow values at the end of the recovery period were indistinguishable from baseline values.

\section{Velocity profile across the width of vessels}

In theory, blood velocity in rigid, straight, nonbranching vessels containing a homogenous fluid should follow a parabolic relation across the width of the vessel, with velocity maximal at the vessel center and approaching zero at the edges. A perfect parabolic relation does not typically occur in blood vessels in vivo, but quadratic relations are used to approximate blood velocity across the width of vessels as small as $\sim 15 \mu \mathrm{m}$. We used two different approaches to measure velocity profiles of retinal arterioles and venules.

\section{Parallel line scans}

High-frequency line scans parallel to the vessel lumen were acquired at multiple locations across the width of the vessel. These line scan images contain angled streaks created by fRBCs as they move through the vessel (Fig. $1 D$ ). Shallower angles indicate higher velocity. For each set of line scans in a single vessel, the fRBC velocity was plotted as a function of the position across the width of the blood vessel. The dataset for each vessel was fit with a quadratic equation. Raw data and the parabolic fit for a representative arteriole and venule are shown in Figure 6 , $A$ and $B$. As expected, velocities were lowest at the vessel edges and highest in the center of the vessel (Fig. $6 C$ ). The mean maximum velocities were $21.0 \mathrm{~mm} / \mathrm{s}$ for arterioles with an average diameter of $28.4 \mu \mathrm{m}$, and $12.4 \mathrm{~mm} / \mathrm{s}$ for venules with an average diameter of $35.7 \mu \mathrm{m}$.

\section{Diagonal line scans}

A second method was used to measure velocity profiles in single trials. High-frequency line scans oriented diagonally across a vessel (Fig. 1E) captured the velocity of individual fRBCs across the vessel width. Velocity was computed at 10 positions along the line. The advantage of this method is that the full velocity profile can be determined from a single line scan trial. Examples of velocity profiles from an arteriole and venule are shown in Figure 7 , $A$ and $B$. Fitting the data from each trial with a quadratic equation yielded an average maximum velocity of 23.7 $\mathrm{mm} / \mathrm{s}$ for arterioles and $11.9 \mathrm{~mm} / \mathrm{s}$ for venules (Fig. 7C).

Although we did not measure velocity profiles in a comprehensive sample of arterioles and venules, the velocity values and parabolic shapes of the profiles were similar between those obtained with parallel and diagonal line scans.

\section{Discussion}

We describe and characterize a technique to measure blood flow in rat retinal vessels. By capturing the passage of individual fRBCs through vessels, and by using a simple method of adjusting fRBC flux to account for the fRBC/RBC ratio and RBCs per volume, absolute blood flow was calculated in vessels ranging from 4 to $70 \mu \mathrm{m}$ in diameter. The accuracy of these measurements was tested a number of different ways. First, blood flow measurements based on fRBC flux were compared to a second independent method of calculating blood flow based 

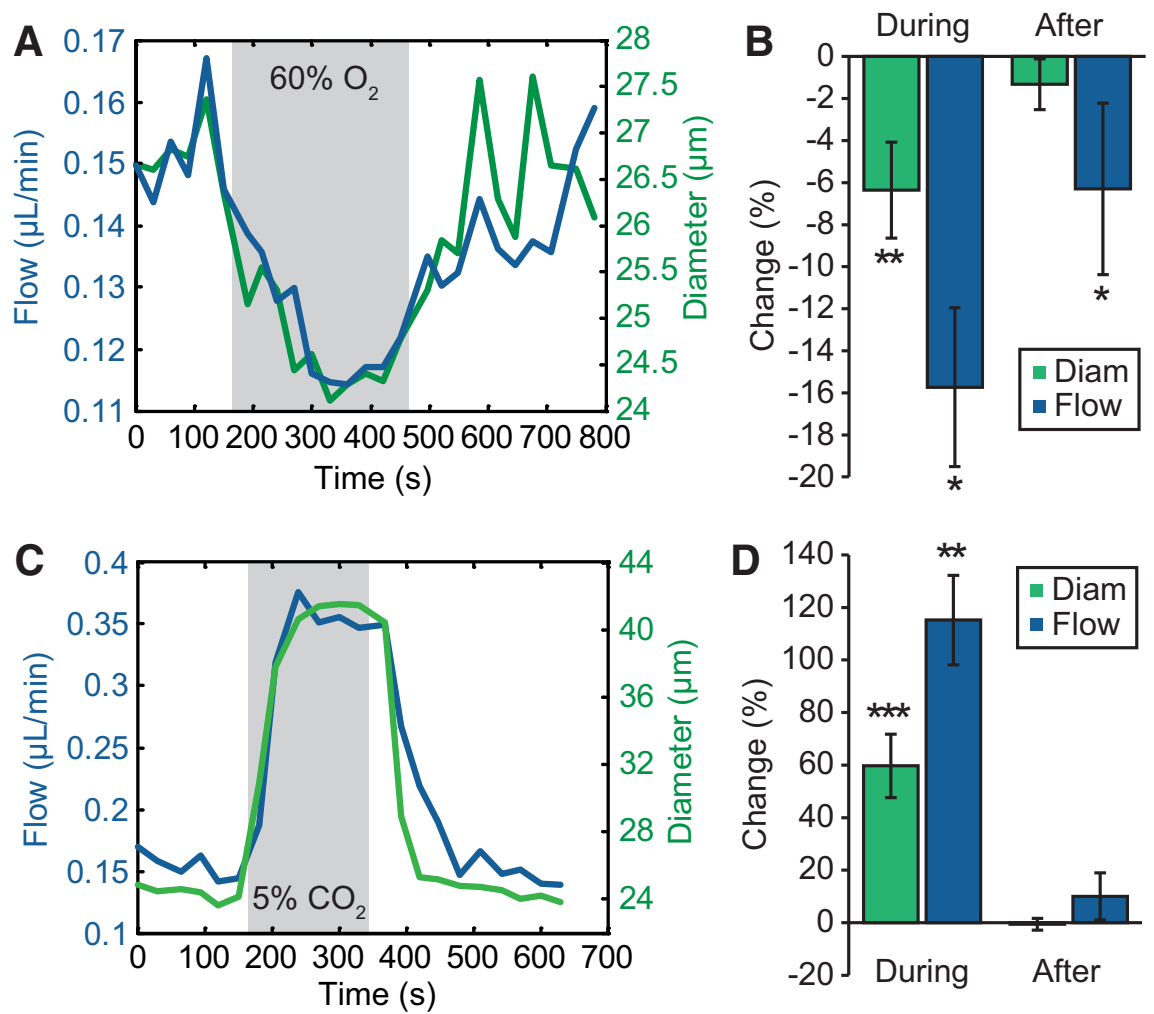

Figure 5 Blood flow changes in primary arterioles in response to hyperoxic and hypercapnic challenge. $\boldsymbol{A}, \boldsymbol{C}$, Representative traces of flow (blue) and diameter (green) in response to hyperoxia $(\boldsymbol{A})$ and hypercapnia $(\boldsymbol{C})$. The period of hyperoxic or hypercapnic challenge is indicated by gray shading. $\boldsymbol{B}, \boldsymbol{D}$, Percentage change in diameter and flow during and after the challenge period. $* p<0.05, * * p<$ 0.01, $* * * p<0.001$. $n=4$ for hyperoxic challenge and $n=3$ for hypercapnic challenge. Diam, Diameter.

on fRBC velocity and vessel diameter. Second, we tested whether blood flow in parent and daughter vessels at bifurcations matched expected values. Third, we observed blood flow changes in response to hypercapnic and hyperoxic challenges. Finally, parabolic velocity profiles were evident in blood vessels as small as $20 \mu \mathrm{m}$ in diameter.

\section{Blood flow at bifurcations}

The validity of blood flux measurements was tested at vessel bifurcations, where the sum of blood flow in daughter branches is equal to flow in the parent vessel. Conservation of blood flow was indeed observed, providing assurance that our method accurately captured the passage of individual RBCs in different caliber vessels. The sum of diameters of daughter vessels did not equal the diameter of the parent vessel. Murray's law predicts vessel diameters required for maximum energetic efficiency at branch points. Theoretically, the radii of parent $\left(r_{p}\right)$ and daughter $\left(r_{d 1}\right.$ and $\left.r_{d 2}\right)$ vessels follows a power law, where $r_{p}^{k}=r_{d 1}^{k}+r_{d 2}^{k}$ with the exponent $k$ ranging from 2 to 3. This was not observed in our bifurcation dataset, where $k$ averaged 6.8. A study of the cerebral vasculature shows a wide variability of $k$ values (Cassot et al., 2009), with the current result close to their reported mean of 6.2. Our results confirm previous findings that Murray's law does not accurately model vessel diameters at bifurcations, particularly in microvessels (Cassot et al., 2009; Hirsch et al., 2012).

\section{Total retinal blood flow}

We have used fRBC flux measurements to determine blood flow in all primary arterioles and venules, providing proof of principle that this simple method can be used to calculate total blood flow in the retinal vasculature. Our blood flow estimate of $3.14 \mu \mathrm{l} / \mathrm{min}$ is on the low end of published values for the rat retina. Those values range from $2.1 \mu \mathrm{l} / \mathrm{min}$ using fluorescently labeled blood cells (Khoobehi et al., 2003) to $6.3 \mu \mathrm{l} / \mathrm{min}$ using OCT (Srinivasan and Radhakrishnan, 2013), and $12.6 \mu \mathrm{l} / \mathrm{min}$ using microsphere tracking (Leskova et al., 2013; Shih et al., 2014). Anesthesia has a strong effect on blood flow. In an OCT study, retinal blood flow was $3.3 \mu \mathrm{l} / \mathrm{min}$ under ketamine/xylazine and $6.4 \mathrm{ml} / \mathrm{min}$ under isoflurane/xylazine (Choi et al., 2012). Isoflurane is a known vasodilator (Franceschini et al., 2010).

The blood flow we measured can also be expressed as $0.42 \mathrm{ml} / \mathrm{min} / \mathrm{g}$, using an average retina weight of $7.5 \mathrm{mg}$ (Shih et al., 2014). This blood flow value is similar to previous measurements made in rabbit (Xuan et al., 1999), cat (Roth and Pietrzyk, 1994; Ahmed et al., 2001), and mouse (Muir et al., 2012), although differences in measurement technique and anesthesia limit the value of these comparisons (Schmetterer and Kiel, 2012). We also 

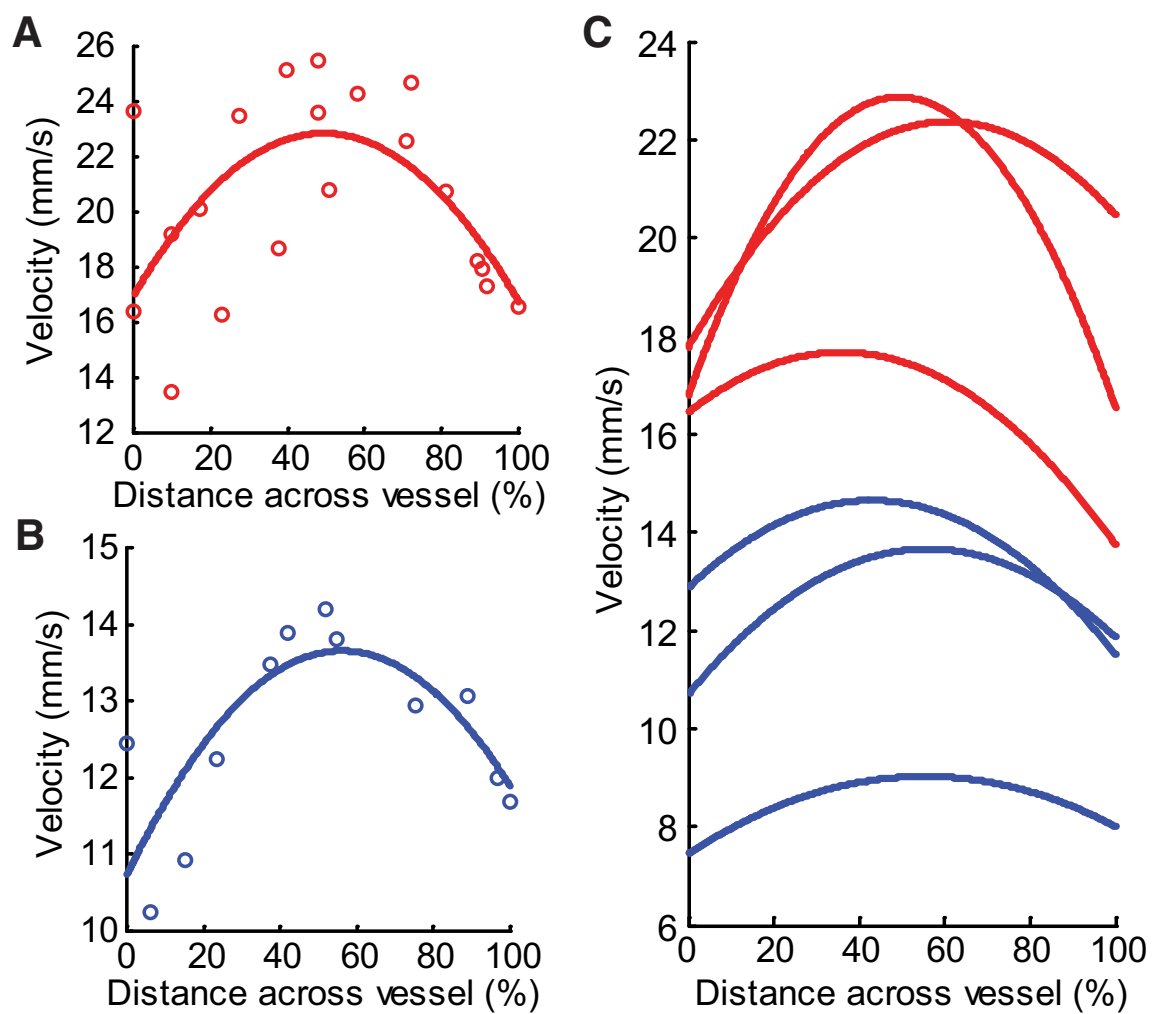

Figure 6 RBC velocity profiles across the width of blood vessels using parallel line scans. $\boldsymbol{A}, \boldsymbol{B}$, Velocity was determined at many points across the width of an arteriole $(\boldsymbol{A})$ and a venule $(\boldsymbol{B})$ by positioning the line scan at different points within the vessel lumen. Velocity was calculated from the slope of fRBC streaks in line scan images (see text for details). Velocity measurements were fit with a second-order polynomial (solid lines). C, Parabolic fits of RBC velocities for individual arterioles (red) and venules (blue).

noted a consistent blood flow underestimation of $12.2 \%$ in venules compared with arterioles. The discrepancy is likely a systematic measurement error. Venules have larger diameters than arterioles, and some fRBCs within venules may have been out of the plane of focus and too dim to be detected.

\section{Functional challenge}

The vessel diameter and blood flow changes we observed in response to hyperoxia and hypercapnia were similar to published values (Kiss et al., 2002; Sato et al., 2003; Gilmore et al., 2005; Venkataraman et al., 2006; Sehi et al., 2012; Werkmeister et al., 2014), and the time course of the blood flow changes seen were comparable to those previously observed in the rat (Hétu et al., 2013). The Hagen-Poiseuille relation predicts that under constant perfusion pressure, blood flow should vary as the fourth power of vessel diameter. In practice, blood flow deviates from this ideal relation. In previous studies, hypercapnia and hyperoxia produced blood flow changes that were smaller (Sato et al., 2003) or larger (Chung et al., 1999; Kiss et al., 2002; Gilmore et al., 2005) than the predicted change. The blood flow changes we observed during hypercapnia and hyperoxia were smaller than predicted by the fourth power relation. The reason for this discrepancy is unclear. Hyperoxic and hypercapnic challenge will have wide systemic effects that could lead to significant changes in perfusion pressure at the vessels being monitored.

\section{Comparison to other methods of measuring blood flow}

Variations of the fRBC imaging method have been used over the past 30 years to monitor blood flow (Sarelius and Duling, 1982; Zimmerhackl et al., 1983; Unthank et al., 1993; Collins et al., 1998; Schulte et al., 2003; Wright and Harris, 2008; Kornfield and Newman, 2014). fRBC imaging has been used to measure capillary flux and velocity by tracking the movement of labeled cells in video frames (Ben-Nun et al., 1992; Yamaguchi et al., 1992; Hudetz et al., 1995; Ben-Nun, 1996; Parthasarathi et al., 1999; Seylaz et al., 1999; Krolo and Hudetz, 2000; Schulte et al., 2003; Reyes-Aldasoro et al., 2008; Wright and Harris, 2008; Wang et al., 2011). With advances in imaging technology, fRBCs have also been tracked with confocal microscopy (Villringer et al., 1994; Pinard et al., 2002; Tomita et al., 2011) and scanning laser ophthalmoscopy (Wajer et al., 2000). A technique for computing absolute blood flow in human retinas by imaging fRBCs with scanning laser ophthalmoscopy has been patented (U.S. Patent US6554775 B1). In the current study, we combined numerous existing methodological techniques with highspeed confocal line scans, allowing us to measure absolute blood flow in large vessels as well as capillaries, 

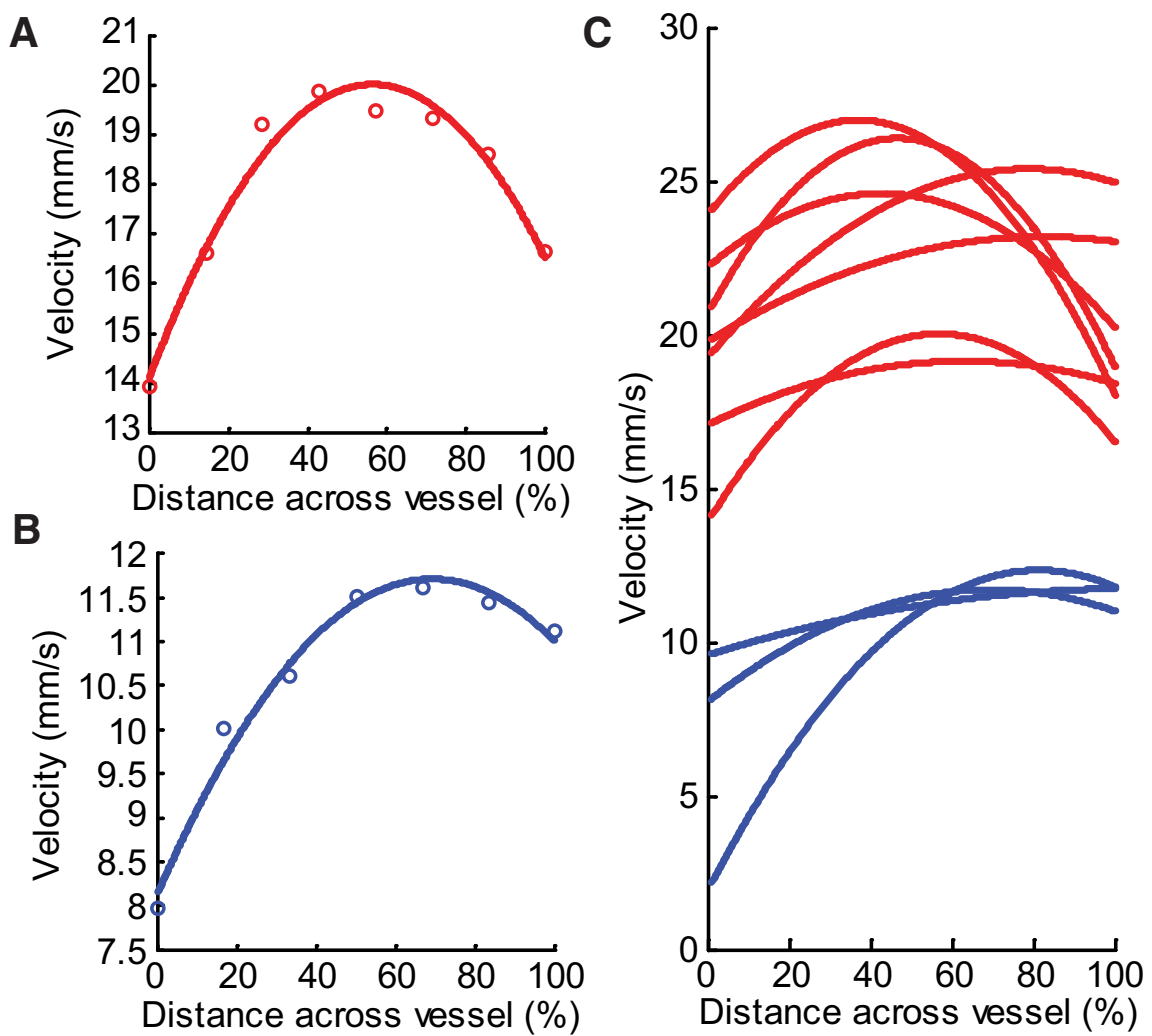

Figure $7 \mathrm{RBC}$ velocity profiles across the width of blood vessels using diagonal line scans. $\boldsymbol{A}, \boldsymbol{B}$, Velocity was determined at many points across the width of an arteriole $(\boldsymbol{A})$ and a venule $(\boldsymbol{B})$ by measuring the angle of fRBC streaks along the diagonal line scan. Velocity measurements were fit with a second-order polynomial (solid lines). $\boldsymbol{C}$, Parabolic fits of RBC velocities for individual arterioles (red) and venules (blue).

and affording significant insights into blood flow dynamics in the retina.

Several groups have developed sophisticated techniques for measuring components of blood flow without cell labeling. Laser scanning microscopy can generate 3D maps of velocity and flux in normal and tumorous brain tissue (Kamoun et al., 2010), an approach particularly valuable in tissues with 3D vessel structures. Crosscorrelation algorithms can extract velocity and flow data from high-speed video recordings in rat muscle preparations (Ortiz et al., 2014), and RBC velocity can be measured in human retinal capillaries using scanning laser ophthalmoscopy (Bedggood and Metha, 2012). Calculating blood flow from unlabeled blood is less invasive than using fRBCs, and the methodologies cited above benefit from high temporal and spatial resolution. The strength of our method lies in its comparative simplicity: it can be used with any confocal microscope system with linescanning capabilities and uses relatively simple analysis procedures. Further, our method can extract multiple parameters (flux, velocity, and diameter) from a single acquisition and can be used in concert with other blood flow measurement techniques including laser speckle flowmetry (Srienc et al., 2010).

Our approach to measuring absolute blood flow has distinct advantages over other optical methods that are typically applied in human retinas. Measurements based on bidirectional laser Doppler velocimetry, the retinal vessel analyzer, and OCT are limited to vessels $>30 \mu \mathrm{m}$ in diameter and are at their most accurate in large-diameter vessels. FD-OCT applied in the rat retina cannot measure blood flow in vessels $<30 \mu \mathrm{m}$ (Werkmeister et al., 2014). In contrast, our technique can be used to calculate flow in retinal vessels of all sizes in the rat retina. Unlike other optical methods of measuring blood flow, which require sophisticated calculations to extract flow values, our technique is straightforward. It is based on simple in vivo and in vitro cell counts, which we have shown to be reliable and accurate.

No gold standard technique exists for measuring retinal blood flow in animals or humans. However, the approach we describe can be applied easily and inexpensively, and can provide quantitative blood flow values for vessels of all sizes. Unlike most previous techniques for measuring fRBC flux, which detect changes in flux during stimulation, the present method combines existing techniques to calculate absolute flow with millisecond resolution. Our technique can be applied to other species and can be used to quantify blood flow change in both normal and pathological retinas.

\section{Methodological limitations}

One limitation of our method is that it uses RBC flux as a proxy for blood flow. Calculated values of blood flow in 
individual vessels will not perfectly represent the flow of whole blood, which also comprises plasma, white blood cells, and other particulate matter. Therefore, care must be taken when using this method to compare flows between vessels. Hematocrit is heterogeneous in individual vessels and varies most in capillaries (Pries et al., 1995; Ganesan et al., 2010; Gould and Linninger, 2015), where the coefficient of variation is 0.60 (compared to 0.41 in arterioles and venules; Pries et al., 1995). Further, the Fahraeus effect, defined as the decrease in hematocrit that accompanies decreasing vessel diameter, could make direct comparisons of blood flow between vessels of different sizes difficult (Barbee and Cokelet, 1971). However, in our dataset, estimates of blood flow based on RBC velocity and vessel diameter (which do not depend on hematocrit) yielded values very close to those calculated from RBC flux across the entire vascular network (Fig. 2), indicating that systematic hematocrit variations did not measurably alter our ability to accurately measure blood flow.

Although the difficulties that arise from hematocrit differences should be kept in mind, many currently employed methodologies rely on RBC flux to calculate blood flow and are subject to the same limitations as our techniques. Plasma-borne fluorescent tracers can be used to measure blood flow, an approach that avoids the problem of inhomogeneous hematocrit by measuring plasma flow instead of particulate flow. However, these angiographic techniques have limitations of their own (Schmetterer and Garhofer, 2007). The dye dilution technique, which tracks the transit time of injected fluorescein through the circulation, relies on a number of assumptions (Pournaras and Riva, 2013), including the assumption that all of the blood entering a retinal region from a primary arteriole exits that region from the corresponding venule. Schmetterer and Garhofer (2007) conclude that retinal blood flow measurements based on fluorescein angiography may not be reliable, particularly under pathological conditions. In addition, angiography techniques do not capture the transit time of the quantal unit of oxygen delivery, the red blood cell (Baker et al., 1980; Tomic et al., 2001). Tomic et al (2001) directly compared blood flow measurements in the monkey retina made using fluorescein angiograms and labeled microspheres. They found that there was only a weak correlation between blood flow values measured by the two techniques and concluded that mean transit time measurements made using angiography do not accurately measure retinal blood flow.

Another limitation of our method is that it uses confocal line scans, which can only be performed on one vessel at a time if high temporal resolution is to be preserved. Because the technique involves blood draws and reinjection of labeled blood cells, it is unlikely to be favored in human subjects over less invasive, though also less direct, techniques for measuring blood flow. However, the technique is particularly useful in animal studies, where flow can be measured in all vessels, regardless of size, and invasiveness is not a concern.

\section{Parabolic velocity profiles}

We measured the velocity of fRBCs using confocal line scans to determine velocity profiles across the width of primary arterioles and venules. The profiles of vessels between 20 and $50 \mu \mathrm{m}$ in diameter were roughly parabolic. The two methods used to capture velocity profiles, parallel and diagonal line scans, yielded similar data. Diagonal line scans require only a single trial to sample the entire profile and are therefore not subject to intertrial shifts in velocity, making them preferable to parallel scans. The advantages and limitations of using angled line scans have been discussed previously (Kamoun et al., 2010). The maximum velocities for arterioles and venules obtained in this study match published values well (Doblhoff-Dier et al., 2014), although they are below velocities measured using fluorescent microspheres (Lorentz et al., 2008).

The parabolic velocity profiles we obtained resemble those reported for larger vessels but do not perfectly match theoretical estimates. There are a number of reasons for this. First, we cannot capture the maximum fRBC velocity within a vessel due to the relatively large depth of field of our imaging system. Velocity measurements in the center of a vessel in the $x-y$ plane will include velocity values from RBCs at the edges of the vessel in the $z$-plane. Therefore, our estimates of maximum velocity are underestimated and approximate the average fRBC velocity. This will cause the resulting quadratic fits to be flatter than expected. Other rheological factors also contribute to blunting at the apex of the parabolic blood velocity profiles, an observation reported previously (Rovainen et al., 1993; Parthasarathi et al., 1999; Logean et al., 2003; Zhong et al., 2011). Second, although some studies detect zero velocity at vessel edges using Doppler-based systems (Yazdanfar et al., 2003; Zhi et al., 2011), we did not. This is not surprising for vessels with diameters ranging from 20 to $50 \mu \mathrm{m}$, where the width of a single RBC represents a significant fraction of the vessel diameter. As vessel diameter decreases, individual RBCs take up a proportionally larger area of the lumen, and their interactions with each other and the vessel wall disrupt laminar flow (Zhong et al., 2011).

\section{Conclusions}

Our results demonstrate that blood flow can be calculated simply and accurately in vessels from 4 to $70 \mu \mathrm{m}$ in diameter by imaging fRBCs with ultrafast line scans, and scaling those counts using the number of RBCs and fRBCs per volume of blood. Flow estimates obtained from this procedure match those calculated from independent measurements of RBC velocity and vessel diameter. Flow at vessel bifurcations confirms the accuracy of the technique. Measurements of total blood flow in the retina and velocity profiles across the width of vessels are easily obtained using fRBC tracking. The method will prove useful in future studies of blood flow and metabolism in the retina and throughout the CNS. 


\section{References}

Ahmed J, Pulfer MK, Linsenmeier RA (2001) Measurement of blood flow through the retinal circulation of the cat during normoxia and hypoxemia using fluorescent microspheres. Microvascular Research 62:143-153. CrossRef Medline

Attwell D, Buchan AM, Charpak S, Lauritzen M, MacVicar BA, Newman EA (2010) Glial and neuronal control of brain blood flow. Nature 468:232-243. CrossRef Medline

Autio J, Kawaguchi H, Saito S, Aoki I, Obata T, Masamoto K, Kanno I (2011) Spatial frequency-based analysis of mean red blood cell speed in single microvessels: investigation of microvascular perfusion in rat cerebral cortex. PLoS One 6:e24056. CrossRef Medline

Baker CH, Sutton ET, Davis DL (1980) Microvessel mean transit time and blood flow velocity of sulfhemoglobin-RBC. Am J Physiol 238:H745-H749. Medline

Barbee JH, Cokelet GR (1971) The Fahraeus effect. Microvascular Research 3:6-16. Medline

Bedggood P, Metha A (2012) Direct visualization and characterization of erythrocyte flow in human retinal capillaries. Biomed Opt Express 3:3264-3277. CrossRef Medline

Ben-Nun J (1996) Comparative flow velocity of erythrocytes and leukocytes in feline retinal capillaries. Invest Ophthalmol Vis Sci 37:1854-1859. Medline

Ben-Nun J, Alder V, Thompson D, Constable IJ (1992) Flow patterns of blood cells in the retinal capillaries. Retinal capillary flow patterns. Int Ophthalmol 16:81-89. Medline

Cassot F, Lauwers F, Lorthois S, Puwanarajah P, Duvernoy H (2009) Scaling laws for branching vessels of human cerebral cortex. Microcirculation 16:331-344. CrossRef Medline

Cheng H, Nair G, Walker TA, Kim MK, Pardue MT, Thulé PM, Olson DE, Duong TQ (2006) Structural and functional MRI reveals multiple retinal layers. Proc Natl Acad Sci U S A 103:17525-17530. CrossRef Medline

Chhatbar PY, Kara P (2013) Improved blood velocity measurements with a hybrid image filtering and iterative Radon transform algorithm. Front Neurosci 7:106. CrossRef Medline

Choi W, Baumann B, Liu JJ, Clermont AC, Feener EP, Duker JS, Fujimoto JG (2012) Measurement of pulsatile total blood flow in the human and rat retina with ultrahigh speed spectral/Fourier domain OCT. Biomed Opt Express 3:1047-1061. CrossRef Medline

Chung HS, Harris A, Halter PJ, Kagemann L, Roff EJ, Garzozi HJ, Hosking SL, Martin BJ (1999) Regional differences in retinal vascular reactivity. Invest Ophthalmol Vis Sci 40:2448-2453. Medline

Collins DM, McCullough WT, Ellsworth ML (1998) Conducted vascular responses: communication across the capillary bed. Microvascular Research 56:43-53. CrossRef Medline

De la Garza BH, Muir ER, Li G, Shih YY, Duong TQ (2011) Blood oxygenation level-dependent (BOLD) functional MRI of visual stimulation in the rat retina at 11.7 T. NMR Biomed 24:188-193. CrossRef Medline

Dirnagl U, Villringer A, Einhäupl KM (1992) In-vivo confocal scanning laser microscopy of the cerebral microcirculation. J Microsc 165: 147-157. Medline

Doblhoff-Dier V, Schmetterer L, Vilser W, Garhöfer G, Gröschl M, Leitgeb RA, Werkmeister RM (2014) Measurement of the total retinal blood flow using dual beam Fourier-domain Doppler optical coherence tomography with orthogonal detection planes. Biomed Opt Express 5:630-642. CrossRef Medline

Franceschini MA, Radhakrishnan H, Thakur K, Wu W, Ruvinskaya S, Carp S, Boas DA (2010) The effect of different anesthetics on neurovascular coupling. Neuroimage 51:1367-1377. CrossRef Medline

Ganesan P, He S, Xu H (2010) Analysis of retinal circulation using an image-based network model of retinal vasculature. Microvascular Research 80:99-109. CrossRef Medline

Garcia JP Jr, Garcia PT, Rosen RB (2002) Retinal blood flow in the normal human eye using the canon laser blood flowmeter. Ophthalmic Res 34:295-299. Medline Medline
Garhofer G, Zawinka C, Resch H, Kothy P, Schmetterer L, Dorner GT (2004a) Reduced response of retinal vessel diameters to flicker stimulation in patients with diabetes. $\mathrm{Br} \mathrm{J}$ Ophthalmol 88:887-891.

Garhöfer G, Zawinka C, Resch H, Huemer KH, Schmetterer L, Dorner GT (2004b) Response of retinal vessel diameters to flicker stimulation in patients with early open angle glaucoma. J Glaucoma 13:340-344. Medline

Garhofer G, Werkmeister R, Dragostinoff N, Schmetterer L (2012) Retinal blood flow in healthy young subjects. Invest Ophthalmol Vis Sci 53:698-703. CrossRef Medline

Gilmore ED, Hudson C, Preiss D, Fisher J (2005) Retinal arteriolar diameter, blood velocity, and blood flow response to an isocapnic hyperoxic provocation. Am J Physiol Heart Circ Physiol 288: H2912-H2917. CrossRef Medline

Girouard H, ladecola C (2006) Neurovascular coupling in the normal brain and in hypertension, stroke, and Alzheimer disease. J Appl Physiol 100:328-335. CrossRef Medline

Gould IG, Linninger AA (2015) Hematocrit distribution and tissue oxygenation in large microcirculatory networks. Microcirculation 22:1-18. CrossRef Medline

Guan K, Hudson C, Flanagan JG (2003) Variability and repeatability of retinal blood flow measurements using the Canon Laser Blood Flowmeter. Microvascular Research 65:145-151. Medline

Hétu S, Pouliot M, Cordahi G, Couture R, Vaucher E (2013) Assessment of retinal and choroidal blood flow changes using laser Doppler flowmetry in rats. Curr Eye Res 38:158-167. CrossRef Medline

Hirsch S, Reichold J, Schneider M, Székely G, Weber B (2012) Topology and hemodynamics of the cortical cerebrovascular system. J Cereb Blood Flow Metab 32:952-967. CrossRef Medline

Hudetz AG, Feher G, Weigle CG, Knuese DE, Kampine JP (1995) Video microscopy of cerebrocortical capillary flow: response to hypotension and intracranial hypertension. Am J Physiol 268: $\mathrm{H} 2202-\mathrm{H} 2210$.

Hutchinson EB, Stefanovic B, Koretsky AP, Silva AC (2006) Spatial flow-volume dissociation of the cerebral microcirculatory response to mild hypercapnia. Neuroimage 32:520-530. CrossRef Medline

Kamoun WS, Chae SS, Lacorre DA, Tyrrell JA, Mitre M, Gillissen MA, Fukumura D, Jain RK, Munn LL (2010) Simultaneous measurement of RBC velocity, flux, hematocrit and shear rate in vascular networks. Nat Methods 7:655-660. CrossRef Medline

Khoobehi B, Peyman GA, Carnahan LG, Hayes RL (2003) A novel approach for freeze-frame video determination of volumetric blood flow in the rat retina. Ophthalmic Surg Lasers Imaging 34:505-514. Medline

Kim KJ, Filosa JA (2012) Advanced in vitro approach to study neurovascular coupling mechanisms in the brain microcirculation. J Physiol 590:1757-1770. CrossRef Medline

Kiss B, Polska E, Dorner G, Polak K, Findl O, Mayrl GF, Eichler HG, Wolzt M, Schmetterer L (2002) Retinal blood flow during hyperoxia in humans revisited: concerted results using different measurement techniques. Microvascular Research 64:75-85. CrossRef Medline

Kleinfeld D, Mitra PP, Helmchen F, Denk W (1998) Fluctuations and stimulus-induced changes in blood flow observed in individual capillaries in layers 2 through 4 of rat neocortex. Proc Natl Acad Sci U S A 95:15741-15746. Medline

Kornfield TE, Newman EA (2014) Regulation of blood flow in the retinal trilaminar vascular network. J Neurosci 34:11504-11513. CrossRef Medline

Krolo I, Hudetz AG (2000) Hypoxemia alters erythrocyte perfusion pattern in the cerebral capillary network. Microvascular Research 59:72-79. CrossRef Medline

Leitgeb RA, Werkmeister RM, Blatter C, Schmetterer L (2014) Doppler optical coherence tomography. Prog Retin Eye Res 41:26-43. CrossRef Medline

Leskova W, Watts MN, Carter PR, Eshaq RS, Harris NR (2013) Measurement of retinal blood flow rate in diabetic rats: disparity between techniques due to redistribution of flow. Invest Ophthalmol Vis Sci 54:2992-2999. CrossRef Medline 
Logean E, Schmetterer L, Riva CE (2003) Velocity profile of red blood cells in human retinal vessels using confocal scanning laser Doppler velocimetry. Laser Physics 13:45-51.

Lorentz K, Zayas-Santiago A, Tummala S, Kang Derwent JJ (2008) Scanning laser ophthalmoscope-particle tracking method to assess blood velocity during hypoxia and hyperoxia. Adv Exp Med Biol 614:253-261. CrossRef Medline

Muir ER, Rentería RC, Duong TQ (2012) Reduced ocular blood flow as an early indicator of diabetic retinopathy in a mouse model of diabetes. Invest Ophthalmol Vis Sci 53:6488-6494. CrossRef Medline

Ortiz D, Briceño JC, Cabrales P (2014) Microhemodynamic parameters quantification from intravital microscopy videos. Physiol Meas 35:351-367. CrossRef Medline

Osborne NN, Casson RJ, Wood JP, Chidlow G, Graham M, Melena $J$ (2004) Retinal ischemia: mechanisms of damage and potential therapeutic strategies. Prog Retin Eye Res 23:91-147. CrossRef Medline

Parthasarathi AA, Japee SA, Pittman RN (1999) Determination of red blood cell velocity by video shuttering and image analysis. Ann Biomed Eng 27:313-325. Medline

Pinard E, Nallet H, MacKenzie ET, Seylaz J, Roussel S (2002) Penumbral microcirculatory changes associated with peri-infarct depolarizations in the rat. Stroke 33:606-612. Medline

Pournaras CJ, Riva CE (2013) Retinal blood flow evaluation. Ophthalmologica 229:61-74. CrossRef Medline

Pries AR, Secomb TW, Gaehtgens P (1995) Structure and hemodynamics of microvascular networks: heterogeneity and correlations. Am J Physiol 269:H1713-H1722. Medline

Reyes-Aldasoro CC, Akerman S, Tozer GM (2008) Measuring the velocity of fluorescently labelled red blood cells with a keyhole tracking algorithm. J Microsc 229:162-173. CrossRef Medline

Riva CE, Grunwald JE, Sinclair SH, Petrig BL (1985) Blood velocity and volumetric flow rate in human retinal vessels. Invest Ophthalmol Vis Sci 26:1124-1132. Medline

Roth S, Pietrzyk Z (1994) Blood flow after retinal ischemia in cats. Invest Ophthalmol Vis Sci 35:3209-3217. Medline

Rovainen CM, Woolsey TA, Blocher NC, Wang DB, Robinson OF (1993) Blood flow in single surface arterioles and venules on the mouse somatosensory cortex measured with videomicroscopy, fluorescent dextrans, nonoccluding fluorescent beads, and computer-assisted image analysis. J Cereb Blood Flow Metab 13:359-371. CrossRef Medline

Santisakultarm TP, Cornelius NR, Nishimura N, Schafer AI, Silver RT, Doerschuk PC, Olbricht WL, Schaffer CB (2012) In vivo twophoton excited fluorescence microscopy reveals cardiac- and respiration-dependent pulsatile blood flow in cortical blood vessels in mice. Am J Physiol Heart Circ Physiol 302:H1367-H1377. CrossRef Medline

Sarelius IH, Duling BR (1982) Direct measurement of microvessel hematocrit, red cell flux, velocity, and transit time. Am J Physiol 243:H1018-H1026. Medline

Sato E, Sakamoto T, Nagaoka T, Mori F, Takakusaki K, Yoshida A (2003) Role of nitric oxide in regulation of retinal blood flow during hypercapnia in cats. Invest Ophthalmol Vis Sci 44:4947-4953. Medline

Schaffer CB, Friedman B, Nishimura N, Schroeder LF, Tsai PS, Ebner FF, Lyden PD, Kleinfeld D (2006) Two-photon imaging of cortical surface microvessels reveals a robust redistribution in blood flow after vascular occlusion. PLoS Biol 4:e22. CrossRef

Schmetterer L, Garhofer G (2007) How can blood flow be measured? Surv Ophthalmol 52[Suppl2]:S134-S138. CrossRef Medline

Schmetterer L, Kiel JW (2012) Ocular blood flow. New York: Springer Science \& Business Media.

Schulte ML, Wood JD, Hudetz AG (2003) Cortical electrical stimulation alters erythrocyte perfusion pattern in the cerebral capillary network of the rat. Brain Res 963:81-92. Medline

Sehi M, Tsui E, Cheng R, Wan J, Wong T, Dorner S, Fisher J, Hudson C (2012) Relative magnitude of vascular reactivity in the major arterioles of the retina. Microvascular Research 83:200-204. CrossRef Medline

Seylaz J, Charbonné R, Nanri K, Von ED, Borredon J, Kacem K, Méric $P$, Pinard E (1999) Dynamic in vivo measurement of erythrocyte velocity and flow in capillaries and of microvessel diameter in the rat brain by confocal laser microscopy. J Cereb Blood Flow Metab 19:863-870. CrossRef Medline

Shahidi AM, Patel SR, Huang D, Tan O, Flanagan JG, Hudson C (2014) Assessment of total retinal blood flow using Doppler Fourier domain optical coherence tomography during systemic hypercapnia and hypocapnia. Physiol Rep 2:e12046. CrossRef Medline

Shahidi M, Shakoor A, Blair NP, Mori M, Shonat RD (2006) A method for chorioretinal oxygen tension measurement. Curr Eye Res 31: 357-366. CrossRef Medline

Shahidi M, Wanek J, Blair NP, Mori M (2009) Three-dimensional mapping of chorioretinal vascular oxygen tension in the rat. Invest Ophthalmol Vis Sci 50:820-825. CrossRef Medline

Shih YY, De la Garza BH, Huang S, Li G, Wang L, Duong TQ (2014) Comparison of retinal and cerebral blood flow between continuous arterial spin labeling MRI and fluorescent microsphere techniques. $\mathrm{J}$ Magn Reson Imaging 40:609-615. CrossRef Medline

Srienc Al, Kornfield TE, Mishra A, Burian MA, Newman EA (2012) Assessment of glial function in the in vivo retina. In: Astrocytes: methods and protocols (Milner R, ed), pp 499-514. New York: Springer.

Srienc Al, Kurth-Nelson ZL, Newman EA (2010) Imaging retinal blood flow with laser speckle flowmetry. Front Neuroenerg 2:128. CrossRef Medline

Srinivasan VJ, Radhakrishnan H (2013) Total average blood flow and angiography in the rat retina. J Biomed Opt 18:76025. CrossRef Medline

Tayyari F, Yusof F, Vymyslicky M, Tan O, Huang D, Flanagan JG, Hudson C (2014) Variability and repeatability of quantitative, fourier-domain optical coherence tomography Doppler blood flow in young and elderly healthy subjects. Invest Ophthalmol Vis Sci 55:7716-7725. CrossRef

Tomic L, Mäepea O, Sperber GO, Alm A (2001) Comparison of retinal transit times and retinal blood flow: a study in monkeys. Invest Ophthalmol Vis Sci 42:752-755. Medline

Tomita M, Tomita Y, Unekawa M, Toriumi H, Suzuki N (2011) Oscillating neuro-capillary coupling during cortical spreading depression as observed by tracking of FITC-labeled RBCs in single capillaries. Neuroimage 56:1001-1010. CrossRef Medline

Unthank JL, Lash JM, Nixon JC, Sidner RA, Bohlen HG (1993) Evaluation of carbocyanine-labeled erythrocytes for microvascular measurements. Microvascular Research 45:193-210. CrossRef Medline

Venkataraman ST, Hudson C, Fisher JA, Flanagan JG (2006) Novel methodology to comprehensively assess retinal arteriolar vascular reactivity to hypercapnia. Microvascular Research 72:101-107. CrossRef Medline

Villringer A, Them A, Lindauer U, Einhäupl K, Dirnagl U (1994) Capillary perfusion of the rat brain cortex. An in vivo confocal microscopy study. Circ Res 75:55-62. Medline

Wajer SD, Taomoto M, McLeod DS, McCally RL, Nishiwaki H, Fabry ME, Nagel RL, Lutty GA (2000) Velocity measurements of normal and sickle red blood cells in the rat retinal and choroidal vasculatures. Microvascular Research 60:281-293. CrossRef Medline

Wanek J, Teng PY, Albers J, Blair NP, Shahidi M (2011) Inner retinal metabolic rate of oxygen by oxygen tension and blood flow imaging in rat. Biomed Opt Express 2:2562-2568. CrossRef Medline

Wang Y, Bower BA, Izatt JA, Tan O, Huang D (2007) In vivo total retinal blood flow measurement by Fourier domain Doppler optical coherence tomography. J Biomed Opt 12:041215. CrossRef Medline

Wang Y, Lu A, Gil-Flamer J, Tan O, Izatt JA, Huang D (2009) Measurement of total blood flow in the normal human retina using 
Doppler Fourier-domain optical coherence tomography. Br J Ophthalmol 93:634-637. CrossRef Medline

Wang Z, Yadav AS, Leskova W, Harris NR (2011) Inhibition of 20HETE attenuates diabetes-induced decreases in retinal hemodynamics. Exp Eye Res 93:108-113. CrossRef Medline

Werkmeister RM, Vietauer M, Knopf C, Fürnsinn C, Leitgeb RA, Reitsamer H, Gröschl M, Garhöfer G, Vilser W, Schmetterer L (2014) Measurement of retinal blood flow in the rat by combining Doppler Fourier-domain optical coherence tomography with fundus imaging. J Biomed Opt 19:106008. CrossRef Medline

Wright WS, Harris NR (2008) Ozagrel attenuates early streptozotocin-induced constriction of arterioles in the mouse retina. Exp Eye Res 86:528-536. CrossRef Medline

Xuan B, Zhou YH, Yang RL, Li N, Min ZD, Chiou GC (1999) Improvement of ocular blood flow and retinal functions with puerarin analogs. J Ocul Pharmacol Ther 15:207-216. Medline

Yamaguchi S, Yamakawa T, Niimi H (1992) Red cell velocity and microvessel diameter measurement by a two fluorescent tracer method under epifluorescence microscopy: application to cerebral microvessels of cats. Int J Microcirc Clin Exp 11:403-416. Medline

Yazdanfar S, Rollins AM, Izatt JA (2003) In vivo imaging of human retinal flow dynamics by color Doppler optical coherence tomography. Arch Ophthalmol 121:235-239. Medline

Zhi Z, Cepurna W, Johnson E, Shen T, Morrison J, Wang RK (2011) Volumetric and quantitative imaging of retinal blood flow in rats with optical microangiography. Biomed Opt Express 2:579-591. CrossRef Medline

Zhong Z, Song H, Chui TY, Petrig BL, Burns SA (2011) Noninvasive measurements and analysis of blood velocity profiles in human retinal vessels. Invest Ophthalmol Vis Sci 52:4151-4157. CrossRef Medline

Zimmerhackl B, Parekh N, Brinkhus H, Steinhausen M (1983) The use of fluorescent labeled erythrocytes for intravital investigation of flow and local hematocrit in glomerular capillaries in the rat. Int $\mathrm{J}$ Microcirc Clin Exp 2:119-129. Medline 